\title{
Paratesticular Neoplasm
}

National Cancer Institute

\section{Source}

National Cancer Institute. Paratesticular Neoplasm. NCI Thesaurus. Code C162485.

A benign or malignant neoplasm that affects the paratesticular structures. 